\title{
Potential prescription patterns and errors in elderly adult patients attending public primary health care centers in Mexico City
}

This article was published in the following Dove Press journal:

Clinical Interventions in Aging

II August 2009

Number of times this article has been viewed

\author{
José Antonio Corona-Rojo' \\ Marina Altagracia-Martínez' \\ Jaime Kravzov-Jinich' \\ Laura Vázquez-Cervantes' \\ Edilberto Pérez-Montoya ${ }^{2}$ \\ Consuelo Rubio-Poo ${ }^{3}$ \\ 'Division of Biological Sciences and \\ Health, Metropolitan Autonomous \\ University, Campus Xochimilco \\ (UAM-X), Xochimilco, México; \\ ${ }^{2}$ National Polytechnical Institute \\ (IPN), México DF; ${ }^{3}$ Faculty of Higher \\ Studies - Zaragoza (FES-Zaragoza), \\ National Autonomous University of \\ México (UNAM), México City, México
}

Correspondence: Marina AltagraciaMartínez

Calle La Joya \#I7 casa 5, Colonia San Juan Tepepan, México DF, c.p. 16020 ,

Delegación Xochimilco

Tel +54837250 7098

Fax +55 56060535

Email altagracial4200@lycos.com
Introduction: Six out of every 10 elderly persons live in developing countries.

Objective: To analyze and assess the drug prescription patterns and errors in elderly outpatients attending public health care centers in Mexico City, Mexico.

Materials and methods: A descriptive and retrospective study was conducted in 2007. Fourteen hundred prescriptions were analyzed. Prescriptions of ambulatory adults aged $>70$ years who were residents of Mexico City for at least two years were included. Prescription errors were divided into two groups: (1) administrative and legal, and (2) pharmacotherapeutic. In group 2, we analyzed drug dose strength, administration route, frequency of drug administration, treatment length, potential drug-drug interactions, and contraindications. Variables were classified as correct or incorrect based on clinical literature. Variables for each drug were dichotomized as correct (0) or incorrect (1). A Prescription Index (PI) was calculated by considering each drug on the prescription. SPSS statistical software was used to process the collected data $(95 \%$ confidence interval; $\mathrm{p}<0.05)$.

Results: The drug prescription pattern in elderly outpatients shows that 12 drugs account for $70.72 \%$ (2880) of prescribed drugs. The most prescribed drugs presented potential pharmacotherapeutic errors (as defined in the present study). Acetylsalicylic acid-captopril was the most common potential interaction (not clinically assessed). Potential prescription error was high ( $53 \%$ of total prescriptions). Most of the prescription errors were due to omissions of dosage, administration route, and length of treatment and may potentially cause harm to the elderly outpatients.

Conclusions: A high number of potential prescription errors were found, mainly due to omissions. The drug prescription pattern of the study population is mainly constituted by 12 drugs. The results indicate that prescription quality depends on the number of prescribed drugs per prescription $(\mathrm{p}<0.000)$.

Keywords: elderly, prescription, pattern, error, outpatients, Mexico

\section{Introduction}

Globally, the number of persons aged 60 years or over is expected almost to triple, increasing from 672 million in 2005 to nearly 1.9 billion by 2050 .

In developed countries, $20 \%$ of the population is aged 60 years or over and is projected to be $32 \%$ by 2050 . In the developing world, the proportion of the population aged 60 or over is expected to rise from $8 \%$ in 2005 to close to $20 \%$ by $2050 .{ }^{1}$

In Mexico (a middle income country), in 2004 it was estimated that the population aged 60 years or over would reach 7.9 million, representing $7.5 \%$ of the total population and 3.5 million of them would be aged 70 years or over. In 2010 , the elderly will number 9.9 million (8.9\% of the whole population), 15 million (12.5\%) in 2020, and more than 22 million $(17.5 \%)$ in $2030 .^{2}$ 
The main causes of death in the elderly population in Mexico are cardiovascular diseases (28.6\%), chronic-degenerative diseases such as malignant tumors and cerebrovascular diseases (15.5\%), and diabetes mellitus (11.6\%). Inappropriate medication use is a major patient safety concern, especially for the elderly population. ${ }^{3,4}$ Prescription of medicines is a fundamental component of the health care of elderly people, and optimization of prescribing for this group of patients has become an important public health issue worldwide. ${ }^{5}$

The higher incidence of chronic diseases and degenerative pathologies increases demand for prescription medicines to treat these conditions, alleviate pain, and provide quality of life and well-being, which renders older adults susceptible to the risk of polypharmacy and drug-related illnesses. ${ }^{5-7}$

In Brazil, the frequency of drugs used has been observed in metropolitan areas, with a mean utilization ranging from two to five medications per day, and one third of all elderly take more than five medications simultaneously. ${ }^{6}$ Consequently, elderly patients are at high risk of drug-drug interactions and drug-adverse events that are generally preventable. ${ }^{7-10}$

Gurwitz and colleagues reported that $13 \%$ of preventable prescribing errors detected in ambulatory patients involved drug-drug interactions. ${ }^{8}$

Elderly people consume more medicines than the general population and this trend increases with age, which increases the probability of interactions among several medicines and consequently a major number of adverse effects have been associated with disabling conditions. ${ }^{11-13}$

The inadequate and inappropriate use of medicines and prescription patterns raise unnecessarily the cost of health care. ${ }^{14-16}$ Appropriate use of medicines is of critical importance for achieving good health in patients and for effective and efficient use of health care resources. ${ }^{17}$

It has been documented that prescription errors that appear with major frequency are related to dosage, prescription of medicines to which the patient is allergic, or indication of an inadequate administration route. ${ }^{18}$

Medications are the most common form of therapy. However, irrational and therefore dangerous prescriptions represent a very high economic, social, and health impact on most countries. ${ }^{19}$

In Mexico, few studies exist on drug prescription patterns and errors in elderly people and even fewer in public primary health care centers or ambulatory health systems.

\section{Need for research}

As mentioned earlier, there are an increasing number of elderly patients, which create new health care challenges since they have special needs.

In 2001, a special public health care program was created in order to give universal health care coverage to the elderly population aged over 70 years, including drugs, laboratory tests, and all medical services.

Mexico has an Essential Drug List (EDL) and its use is compulsory for all public institutions (Ministry of Health, federal and state health care centers, "Mexican Social Security Instute" Instituto Mexicano del Seguro Social [IMSS] and "Social Services for State workers Institute" Instituto de Seguridad y Servicios Sociales de los Trabajadores del Estado [ISSSTE]. ${ }^{20-22}$ The design of the Mexican EDL is based on the World Health Organization (WHO) concept of rational use of drugs: efficacy, safety and cost. ${ }^{23}$

Many questions arise regarding prescribing in elderly people included in the special public health care program mentioned above:

- The kind of drugs being prescribed in the ambulatory health care system of the Ministry of Health of the Federal District (SSADF).

- The drugs prescribed, considering the Mexican public health sector's EDL.

- The appropriateness of drug prescribed.

- The frequency and type of prescription errors.

- Potential drug-drug interactions and contraindications.

- The quality level of the drug prescriptions in Mexico DF ambulatory health care system.

The specific goals of this work were (a) to describe drug patterns of use in elderly Mexican population and (b) to analyze the prescriptions to detect possible errors.

\section{Methods}

\section{Study setting}

The Mexican health care system was initially formed with a component of public institutions in order to offer health care services to both the uninsured population, who are usually unsalaried with little economic power (Ministry of Health, or Secretaría de Salud [SSa], as well as the insured population, represented by salaried workers from the formal economic sector of the population (r IMSS, and ISSSTE). The other components of the health care system refer to the private sector, with a broad array of institutions offering health care services to the population with purchasing power. ${ }^{24}$ 
In the public health care system, all prescriptions should be written using only generic names (no brand names are allowed). In the primary health care system (health care centers belonging to Mexico City's Ministry of Health), most of the physicians are general practitioners or without medical specialties (no geriatricians). A maximum of three drugs are allowed to be included in one single prescription, but two or more prescriptions can be used for one single patient. There is no limit for the total number of drugs to be prescribed to one single patient, but different prescription sheets must be used.

There are 210 health care centers of SSADF; 134 of them have a pharmacy. As mentioned earlier, the beneficiaries of those centers are the uninsured population, who are unsalaried with little economic power. There are about 2,213 general physicians.

\section{Inclusion criteria}

Prescriptions of ambulatory adults aged 70 years or over (age was a criteria defined in the health care program analyzed in the present investigation), who were residents of Mexico City for at least two years, and were registered in a health care center of SSADF close to his/her residency. All prescriptions had to be issued during the study period (January to December 2007). All the prescriptions issued during 2007 for elderly people (for the present study it was defined as elderly aged 70 years or over) were included to calculate the sample size. ${ }^{25}$ All prescriptions must include a prescription serial number, the name of the patient, age, home address, weight, gender, diagnosis, drugs (generic name and EDL code number), dose, dosage frequency, route of administration, duration of treatment, and patient and physician signatures.

\section{Exclusion criteria}

All prescriptions that were illegible or not clearly written and did not meet the inclusion criteria were excluded.

\section{Sample size}

The size of the sample was calculated using the formula for a population proportion taken into account the pilot test sample data which resulted in 1,400 prescriptions. Prescriptions were selected randomly. ${ }^{26,27}$

\section{Study design}

A descriptive and retrospective study was conducted.

\section{Study variables}

\section{Continuous and categorical study variables}

Among the continuous variables are the number of drugs prescribed per patient per prescription as a whole and age.
Categorical variables are gender and diagnosis as written on the prescription.

In order to analyze prescription errors, we divided them into two groups: administrative and legal (group 1) and pharmacotherapeutic (group 2) errors. In group 1, we analyzed: 1) EDL code number (included by Mexican General Health Law), 2) physician's signature, 3) physician identification number, 4) number of drugs included in the EDL, and 5) number of drugs prescribed using brand names.

Variables 1 to 5 were dichotomized as included in the prescription (0) and not included (1). When the total sum of all the administrative and legal variables was 0 , the prescription was considered correct (variables 1 to 4 ) and incorrect when the sum was greater than 0 (variables 1 to 5 ).

In group 2, we analyzed drug-dose strength, administration route, frequency of drug administration, treatment length, drug-drug potential interactions, and contraindications. The variables were classified as correct or incorrect based on clinical literature. ${ }^{28-31}$ Variables were dichotomized as correct ( 0 ) or incorrect (1). Inappropriate drug use was considered when the prescribed drug did not comply with EDL guidelines, Beer's criteria, and the corresponding clinical literature ${ }^{20,32-34}$ In other words, inappropriate drug use was when the selection of drug, the dose, route of administration, drug administration frequency, treatment, etc. did not match what is established or recommended in the clinical literature as an appropriate use of drug in the elderly.

\section{Data collection}

SPSS statistical software (version 13; SPSS Inc., Chicago, IL, USA) was used for processing the collected data. Univariate, bivariate, and logistic regression statistical analyses were performed. By using the univariate analysis, patient frequency was calculated with regard to the continuous and categorical variables described above.

\section{Variables at the patient level}

To assess the quality of the prescription by patient, the following variables were considered: 1) number of drugs prescribed per each patient, 2) diagnosis per prescription per patient, 3) age, and 4) gender.

According to the clinical literature on the subject, potential drug-drug interactions and contraindications were identified and quantified. ${ }^{35,36}$ The 12 most prescribed drugs for the 1,400 outpatients during the study period were chosen for this analysis. 


\section{Variables at the prescription level}

Only variables of group 2 were considered to determine prescription quality. To determine prescription quality, a Prescription Index (PI) was calculated by considering each drug on the prescription. Clinical literature was used to revise each drug. The variables were: 1) drug, 2) dose, 3) administration route, 4) dose frequency, 5) treatment length, 6) potential drug-drug interactions, and 7) contraindications. All these variables were dichotomized as correct/incorrect. The value intervals ranged between 0 and 7. For the last two variables (potential drug-drug interactions and contraindications), when the prescribed drug aggravated the patient's health status due to increasing drug toxicity, these effects were 1 when they were present in the prescription and 0 if they were absent.

The PI was calculated as the sum of the values assigned to each of the seven variables, which were divided into the total number of drugs per prescription. These values were categorized as 0 (good quality: without any errors) and greater than 0 up to 0.75 (regular), greater than 0.75 to $1.5(\mathrm{bad})$, and greater than 1.5 (very bad). For any undesirable situation, the prescription quality is assumed as poor or incorrect.

The PI used was also based on what Baber defined in 1995 as a good prescription, although Baber also included the drug cost and patient choice, which was not included in the present study. ${ }^{37}$

\section{Bivariate and multivariate statistical analyses}

The prescription quality rate (by drug and by patient) was compared with the following variables to establish an association: 1) number of prescribed drugs, 2) age, and 3) gender. The Chi-squared test was used for categorical variables and the Student's $t$-test or Mann-Whitney test was used to compare continuous variables. In every case, the relation of the variables with the PI was considered significant when $\mathrm{p}<0.05$.

A logistical regression multivariate analysis was conducted with all the variables that proved significant in the bivariate analysis, both for the prescription quality index by drugs and by patient. Variables with $p<0.05$ were considered statistically significant.

\section{Results}

\section{Results of the continuous and categorical} variables of the study

A total of 1,400 prescriptions were analyzed, corresponding to 1,400 patients, of which $71 \%$ (996) were female and $29 \%$ (404) male. The total amount of patients $(1,400)$ was divided into four age groups: 54\% (760) patients were aged 70-75, $29 \%$ (401) were aged $76-81,13 \%$ (181) were aged $82-87$ and, 4\% (58) were aged 88-99 years, respectively.

It was found that, of a total of 1,400 prescriptions, $61.4 \%$ (859) had one diagnosis, 32\% (447) had two, and 6\% (85) had three, and less than $1 \%$ had four or five diagnoses. The patients' main diagnoses were: $28.5 \%$ (583) hypertension, $14 \%$ (287) type 2 diabetes mellitus, $10 \%$ (204) pharyngitis, $7 \%$ (139) rheumatoid arthritis, 6\% (125) gastritis, 5\% (101) urinary tract diseases, 3.2\% (65) osteoarthritis, 2.3\% (46) peripheral venous insufficiency, $2 \%$ (40) rhinitis, $2 \%(40)$ colitis, $2 \%$ (35) gastrointestinal infections, $2 \%$ (32) backache, and $18 \%(37)$ were other diagnoses each with less than $1 \%$ frequency (total diagnosis frequency was 2,045). Twelve diagnoses represented about $82 \%(2,045)$ of the total diagnoses included in 1,400 prescriptions.

In order to determine drug prescription patterns in the study setting (ambulatory health care centers), the total prescribed medications $(2,880$ drugs $)$ included in all the prescriptions $(1,400)$ were analyzed: $36.6 \%(512)$ included two, $31.50 \%$ (441) three, $30.43 \%$ (426) one, $0.57 \%$ (4) four, $0.36 \%$ (5) five, and $0.57 \%$ (8) six drugs, respectively.

In order to determine the drug prescription, the top 12 drugs found in the total prescriptions $(1,400)$ were: captopril 16.07\% (463 times), naproxen 10.34\% (298), glyburide $8.02 \%$ (231), trimethoprim/sulfamethoxazole 6.18\% (178), ambroxol 4.89\% (141), diclofenac 4.65\% (134), ranitidine 4.4\% (126), acetaminophen 3.9\% (112), metformin 3.71\% (107), acetylsalicylic acid (ASA) 3.47\% (100), B complex $2.56 \%$ (74), and metoprolol $2.53 \%$ (73). Only 12 drugs represented $70.72 \%$ (2,037 drugs) of the total drugs prescribed $(2,880)$ in 1,400 prescriptions.

The Mexican EDL has 24 therapeutic groups. All drugs prescribed $(2,880)$ were classified and quantified by therapeutic group. The major therapeutic groups were: cardiological diseases $22.7 \%$ (656), infectious diseases $17 \%$ (489), rheumatic diseases $15.5 \%$ (446), endocrinological diseases $13.3 \%$ (384), gastroenterological diseases $8.3 \%$ (218), and analgesic $7.56 \%$ (218). Six of the therapeutic groups represented $84.3 \%$ of all the drugs prescribed in 1,400 prescriptions.

\section{Administrative and legal errors found in the analyzed prescriptions (group I)}

The results of the prescription errors in the administrative and legal variables found were: 1) $95 \%$ (1,332 prescriptions) did not have the EDL code numbers, 2$) 97 \%$ (1,359) prescriptions were found with physician's signatures and without them $3 \%(41), 3) 96 \%(1,348)$ prescriptions did not include the 
physician's identification number, and only 4\% (52) of the total prescriptions had the physician's identification number, 4) in $99.99 \%(1,399)$ of prescriptions, the name of the active principal (a constituent of a drug on which the characteristic therapeutic action of the substance largely depends) was included in the EDL and, only one active principal of one drug in one prescription was not included in the EDL, and 5) a total of 13 drugs were written using brand names not generic ones.

\section{Results of errors due to pharmacotherapeutic} variables (group 2)

All 2,880 prescribed drugs were analyzed to estimate the frequency of prescription errors described in the present study methodology. We found that the dose of the drugs $(6 \%)$, drug administration route $(13 \%)$, frequency of dosage timing (1\%), and length of treatment (42\%) were not included in the prescriptions.

Potential drug-drug interactions and contraindications According to the clinical literature, from the total number of elderly prescriptions $(1,400)$ analyzed, it was found that $4 \%$ of patients had the possibility of drug-drug interactions and $9 \%$ had potential contraindications. The most frequent drug-drug interaction was ASA-captopril (30 times). ASA was frequently prescribed in high doses $(500 \mathrm{mg} /$ day $)$. An inadequate relationship was found between drug prescribed and diagnosis, indicating an error in the drug selection $(3 \%)$.

\section{Quality of prescriptions}

When applying the PI as described in the Methods section, it was found that $53 \%$ of all prescriptions did not have a PI equal to zero and only $47 \%$ did. The level of association between the PI and the study variables was determined using Chi-squared test for a confidence interval (CI) of 95\%: (0-1.36)

The bivariate analysis of the PI quality showed that of all variables, the ones with statistical significance were the number of diagnoses per prescription $(95 \% \mathrm{CI}$ : $0.1804-2.7424) ; \mathrm{p}<0.000)$ and number of drugs $(95 \% \mathrm{CI}$ : 0.3085-3.8029); $\mathrm{p}<0.000)$.

\section{Logistic regression}

A multivariate statistical analysis was conducted with the statistically significant variables. The results indicate that prescription quality (as determined by $\mathrm{PI}$ ) depends on the number of prescribed drugs per prescription $(\mathrm{p}<0.000)$. The number of diagnoses was not statistically significant $(\mathrm{p}>0.05)$. Please see Table 1 .
Table I Bivariate analysis and logistic regression results

\begin{tabular}{lll}
\hline Variables & $\begin{array}{l}\text { Bivariate analysis: } \\
\text { Chi-squared test } \\
(\mathbf{9 5 \%} \mathbf{C l}) \mathbf{p}<\mathbf{0 . 0 5}\end{array}$ & $\begin{array}{l}\text { Multivariate } \\
\text { analysis and logistic } \\
\text { regression } \mathbf{p}<\mathbf{0 . 0 5}\end{array}$ \\
\hline Number of diagnoses & 0.000 & 0.077 \\
Number of drugs & 0.000 & 0.000 \\
Gender & 0.343 & - \\
Age & 0.942 & - \\
\hline
\end{tabular}

Abbreviation: $\mathrm{Cl}$, confidence interval.

\section{Discussion}

The drug prescription pattern of the study population (elderly people aged 70 years and over) shows that some drugs like captopril and naproxen are used inappropriately in relation to the most frequent diseases. No high tendency towards polypharmacy (when five or more drugs are used concomitantly), possible drug-drug interactions, and contraindications were found. Very few patients were prescribed with five or more drugs per prescriptions. ${ }^{10}$

The two most frequent diseases in the study population were arterial hypertension (28.5\%) and diabetes mellitus $(14 \%)$, which are also the main causes of death in the Mexican general adult population. Nevertheless, the most prescribed drugs were captopril (463 times, 16.07\%) and naproxen (298 times, 10.34\%). Prescriptions including naproxen, in some cases, were not consistent with the patient diagnosis. Besides, naproxen is included in the Beers's list of potentially inappropriate medications for the elderly. ${ }^{38}$ As mentioned by Fick and colleagues. ${ }^{38}$ Toxic effects of medications and drug-related problems can have profound medical and safety consequences for older adults and affects the health care system economically. Thirty percent of hospital admissions in elderly patients may be linked to drug-related problems or toxic drug-related side effects. ${ }^{38}$ Some risk factors related to nonsteroidal anti-inflammatory drugs (NSAIDs) were documented by Bateman and Kerr. ${ }^{39}$ Serious gastrointestinal (GI) events occurred frequently in patients taking NSAIDs (naproxen) who had not experienced any warning symptoms; it is important to identify factors that increase the risk of serious GI complication and to consider how the risk can be reduced. The risk of GI complication increases linearly with advanced age, a primary risk factor. ${ }^{39}$

Some studies have demonstrated that NSAIDs produced a decline in glomerular filtration rate (GFR) and that the decline in renal function has particular implications for the safe use of NSAIDs therapy in the elderly, since a decrease 
in renal perfusion may place these individuals at increased risk of NSAIDs-induced acute renal impairment. ${ }^{40,41}$ In addition to hemodynamically mediated acute renal failure, other renal syndromes and side effects associated with NSAID use have been characterized. Cyclooxygenase 2 (COX-2) is primarily an inducible enzyme, while COX-1 is constitutively expressed in nearly all normal tissues, but is especially important in the gastrointestinal tract, kidneys, and platelets. ${ }^{40}$

In their study of the effects of celecoxib and naproxen on renal function in the elderly, Whelton and colleagues concluded that COX-2-specific inhibition in healthy elderly may spare renal hemodynamic function, although the effects on sodium excretion, as well as urinary prostaglandin $\mathrm{E}_{2}$, and 6-keto-prostaglandin $\mathrm{F}_{1 \alpha}$ excretion, appear to be similar to those of nonspecific cyclooxygenase inhibitors such as naproxen. ${ }^{40}$

COX-2 inhibitors versus nonselective NSAIDs and their congestive heart failure outcomes in elderly patients were investigated by Mamdani and colleagues and others, and their findings suggest a higher risk of admission for congestive heart failure in users of rofecoxib (COX-2) and nonselective NSAIDs, but not relative to celecoxib, relative to non-NSAID controls. ${ }^{41-44}$

The drug prescription pattern suggests the need to establish rational drug therapy.

Most of the prescription errors (53\%) in group 2 variables were due to omissions of dosage, administration route, and treatment length. Most of the general physicians in the present study refused to comply with the EDL.

The EDL includes clear specifications for the rational use of each drug (patient age, dosage, administration route, treatment length, drug pharmaceutical presentation, drug time frequency, drug-drug interactions, and contraindications). Any one of the prescription errors mentioned above might not contribute to a dangerous health situation for elderly people, but can potentially worsen their condition.

Our results are similar to other studies that have reported inappropriate medication use in an elderly population. ${ }^{3,6,7}$

Prescription quality is poor (53\%), being affected mainly by the number of drugs per patient. Due to the potential drug-drug interactions detected, it seems to us that no risk/ benefit relationship was established among concomitant drug regimens and diagnoses.

Even though the number of potential drug-drug interactions is not high in the present study, it is important to point out that all of them were preventable. ${ }^{45}$ ASA-captopril (the effect of angiotensin-converting enzyme inhibitors may be blunted by ASA administration), allopurinol-captopril (a possible increased risk of Stevens-Johnson syndrome), ASA-furosemide (ASA blocks the diuretic effect of furosemide), metformin-metoprolol ( $\beta$-blocker alters glucose metabolism). The combination of captopril-furosemide can be safe and effective, but (a) a few patients may feel dizzy or lightheaded within an hour of taking the first dose and acute hypotension can occur; (b) hyperkalemia is possible if potassium-sparing diuretics (eg, amiloride, spironolactone, triamterene) and/or potassium supplements are used concurrently; (c) hypokalemia may occur if potassium-depleting diuretics are used (furosemida); (d) severe renal deterioration and failure has been seen in patients with renal arterial stenosis. $^{46}$

Four of the nine potential drug-drug interactions are associated with captopril: captopril-isosorbide (hyperkalemia), ASA-antiacids (antacids decreases salycilate seric concentrations), metformin-ranitidine (increases the risk of lactic acidosis), and enalapril-furosemide (hypotension and renal failure). ${ }^{28,34-36}$ Despite these indications, no clinical assessment was done. The risk/benefit rate of some drugs was assessed, and potential drug-drug interactions were identified based on written prescriptions and clinical literature.

We acknowledge that some of the combinations theoretically reported as undesirable (such as ASA-captopril) depending on the individual patient's health status are frequently used by physicians. Besides, additional information is needed on the timing of administration, laboratory tests, among other parameters.

General physicians should do much better if they prescribe carefully for elderly and observe the EDL guidelines. As can be concluded for this particular group of elderly outpatients, most of the potential drug-drug interactions could be prevented by managing the prescription of antihypertensive drugs and hypoglycemic agents.

The poor quality of prescriptions might be explained by data obtained from health care centers about physician professional's profiles. The average age of doctors is 28 years; they are very young and some have not completed their medical training, have very little experience and have not yet specialized in any medical sciences (general physicians).

The other problem in Mexico is the absence of community pharmacists; none of the health care centers has a pharmacist. The person in charge of the pharmacy is generally not a health professional (has not a bachelor degree in pharmacy) and has less than a ninth degree level of education. 
In the United States and the United Kingdom, professional pharmacists have made great contributions to improve prescribing in the ambulatory elderly population. ${ }^{47,48}$

Despite the substantial commitment of resources from the local Mexican government and others to promote and guarantee the access to drugs to the elderly and needy population, no ongoing information exists on the degree to which the Mexican elderly population is using the broad range of medications available, including prescription and over-the-counter drugs.

The prevention and recognition of drug-related problems in elderly patients and other vulnerable populations is one of the principal quality and safety issues for this decade. ${ }^{38}$ Drug-drug interactions are a preventable cause of morbidity and mortality, yet their consequences in the community are not well characterized. ${ }^{45}$ Mexico City is not an exception to that statement.

The limitations of our study are the reliability of data obtained from prescriptions, which could lead to some measure of bias in our results. No medical records were revised. We used only prescriptions issued during the study period. The lack of information on other products used to treat the diseases presented (eg, use of over-the-counter drugs and herbal products), which might interact with the prescribed drugs and the elimination of prescriptions that were not clearly written could bias our results as a main source of potential prescription errors. As well as the lack of confirmation of the health conditions for which prescriptions were written, the absence of information on other health conditions present and health care outcomes could also bias our results.

\section{Study limitations}

We evaluated potential medication prescription patterns and errors in the elderly adult population. No clinical patient assessment was done; only prescriptions were evaluated. As a retrospective study, its limitations are inherent to the study design. Evaluation of the prescription errors were based on clinical literature, the Mexican EDL, and the updated Beer's guidelines.

\section{Conclusions}

A high number of potential prescription errors were found, mainly due to omissions. The drug prescription pattern of the study population is mainly constituted by 12 drugs. Our results indicate that prescription quality depends on the number of prescribed drugs per prescription $(\mathrm{p}<0.000)$.

\section{Disclosures}

The authors report no conflicts of interest in this work.

\section{References}

1. United Nations, Economics and Social Affairs. World Population Prospects. The 2004 Revision. February 25, 2005. Available from: http://www.un.org/esa/population/publications/WPP2004/ 2004Highlights_finalrevised.pdf. Accessed June 21, 2008.

2. Consejo Nacional de Población. Envejecimiento de la Población en México. Available from: http://www.conapo.gob.mx. Accessed July 6, 2008.

3. Zhan C, Sangl J, Bierman AS, et al. Potentially inappropriate medication use in the community-dwelling elderly: findings from the 1996 Medical Expenditure Panel Survey. JAMA. 2001;286:2823-2829.

4. Murray MD, Callahan CM. Improving medication use for older adults: an integrated research agenda. Ann Intern Med. 2003;139: 425-429.

5. Spinewine A, Schmader KE, Barber N, et al. Appropriate prescribing in elderly people: how well can it be measured and optimised? Lancet. 2007;370:173-184.

6. de Tolêdo Nóbrega O, Melo GF, de Oliveira Karnikowski MG. Pattern of drugs prescribed for community-residing middle-aged and older adults from the outskirts of Brasilia. Brazilian Journal of Pharmaceutical Sciences. 2005;41:271-277.

7. Mallet L, Spinewine A, Huang A. The challenge of managing drug interactions in elderly people. Lancet. 2007;370:185-291.

8. Gurwitz JH, Field TS, Harrold LR, et al. Incidence and preventability of adverse drug events among older persons in the ambulatory setting. JAMA. 2003;289:1107-1116.

9. Shah RR. Drug development and use in the elderly: search for the right dose and dosing regimen (Parts I and II). Br J Clin Pharmacol. 2004;58:452-469.

10. Milton JC. Prescribing for older people. BMJ. 2008;336:606-609.

11. Lázaro M. Envejecimiento, Salud y fármacos. Revista Española de Geriatría Gerontología. 1995;30:59-65.

12. Tapia CR, Cravioto P, Borges-Yañez A, De la Rosa B. Consumo de drogas médicas en población de 60 a 65 años en México. Encuesta Nacional de Adicciones 1993. Revista de Salud Publica de Mexico. 1996;38:458-465.

13. Pérez Ma G, Lares Asseff I, Pérez Ortiz B, et al. Patrones de prescripción y consumo de medicamentos en niños hospitalizados con desnutrición grave. Acta Pediatr Méx. 1999;20:219-224.

14. Durán-González L, Frenk-Mora J, Becerra-Aponte J. La calidad prescriptiva en atención primaria. Salud Publica. 1990;32:181-191.

15. Weintraub M. Medicolegal aspects of iatrogenic injuries. Neurol Clin. 1998;16:217-227.

16. Cohen MR. Preventing daunorubicin (Cerubidine)-doxorubicin mix-ups; to prevent mix-ups, learn to talk to yourself; ongoing potassium chloride concentrate errors kill patients: An issue of cost versus care? Hospit Pharm. 1996;31:184-188.

17. Haaijer-Ruskamp FM, Hoven JL, Mol PGM. A conceptual framework for constructing prescribing quality indicators: a proposal. DURQUIM: Drug Utilisation Research Quality Indicator Meeting. Mechelen, Belgium, 13-15 May 2004. Available from: http://www.euro.who. int/Document/E91322.pdf. Accessed July 17, 2009.

18. Fortescue EB, Kaushal R, Landrigan CP, et al. Prioritizing strategies for preventing medication errors and adverse drug events in pediatric inpatients. Pediatrics. 2003;111:722-729.

19. Garnica-Rodríguez N, Altagracia-Martínez M, Kravzov-Jinich J, Ríos-Castañeda C. Drug prescription patterns and errors in a Mexican general public hospital. A pilot study Journal of Pharmaceutical Finance, Economics and Policy. 2005;14:3-18.

20. Secretaria de Salud (SSa). Cuadro Básico y Catálogo de Medicamentos del Sector Salud. México DF, México. Available from http://www.ssa. gob.mx. Accessed in July 23, 2008. 
21. Durán-González L, Becerra-Aponte J, Franco FM, Kravzov-Jinich J, Viso-Gurovich F, Frenk-Mora J. Uso del cuadro de medicamentos en el primer nivel de atención. Salud Publica. 1990;32:543-551.

22. Kravzov-Jinich J, Altagracia-Martínez M. Changes in the Mexican Essential Drug List. J Soc Adm Pharm. 1994;11:153-159.

23. Management Sciences for Health. Rational Drug Use: Prescribing, Dispensing, Counseling and Adherence in ART Programs. 1985. Available from: http://www.who.int/hiv/amds/capacity/ken_msh_rational. pdf. Accessed October 4, 2008.

24. Arredondo A, Zúñiga A. Economic consequences of epidemiological changes in diabetes in middle-income countries: the Mexican case. Diabetes Care. 2004;27:104-109.

25. World Health Organization. Men, Ageing and Health: Achieving health across the life span. 1999. Available from: http://whqlibdoc.who. int/hq/2001/WHO_NMH_NPH_01.2.pdf. Accessed October 4, 2008.

26. Marques Dos Santos MJ. Probabilidad y Estadística para Ciencias Químico Biológicas. Second edition. México DF, Mexico: UNAM; 2004. p. 1-626.

27. Wayne WD. Bioestadística: Base para el análisis de las ciencias de la salud. Second edition. México DF, México: Limusa; 1980.

28. Semia TP, Beizer JL, Higbee MD. Geriatric Dosage Handbook. Eleventh edition; Hudson, OH: Lexi-Comp Inc., APhA; 2006.

29. Kane RL, Ouslander JG, Abrass IB. Essentials of Clinical Geriatrics. Fourth edition. New York, NY: McGraw Hill; 1999.

30. Miller SW. Geriatric drug therapy. In: Helms RA, Quan DJ, Herfindal ET, Gourley DR, editors. Textbook of Therapeutics. Drug \& Disease Management. Eighth edition. Philadelphia, PA: Lippincott Williams and Wilkins; 2006. p. 1829-1844.

31. Drug Facts and Comparisons. St. Louis, MO: Wolters Kluwer Health/ Facts and Comparisons Press; 2007.

32. Hardman JG, Limbird LE, editors. Goodman \& Gilman's. The Pharmacological Basis of Therapeutics. Tenth edition. New York, NY: McGraw-Hill; 2001.

33. Lindblad CI, Gray SL, Guay DRP, Hajjar ER, McCarthy T, Hanlon JT. Geriatrics. In: DiPiro JT, Talbert RL, Yee GC, Matzke GR, Wells BG, Posey LM, editors. Pharmacotherapy. A Pathophysiologic Approach. Sixth edition. New York, NY; McGraw-Hill; 2005. p. 103-114.

34. Landefeld CS, Palmer RM, Johnson MA, Johnston CB, Lyons WL, editors. Current Geriatric Diagnosis and Treatment. New York, NY: McGraw-Hill; 2004.

35. Tatro DS, editor. Drugs Interaction Facts. St. Louis, MO; Wolters Kluwer; 2007.
36. Baxter K, editor. Stockey's Drug Interactions. Pocket Companion. London, UK: Pharmaceutical Press; 2008.

37. Baber N. What constitutes good prescribing? BMJ. 1995;310: 923-925.

38. Fick DM, Cooper JW, Wade WE, Waller JL, Maclean JR, Beers MH. Updating the Beers criteria for potentially inappropriate medication use in older adults: results of a US consensus panel of experts. Arch Intern Med. 2003;163:2716-2724.

39. Bateman N, Kerr S. Gastrointestinal disorders. In: Lee A, editor. Adverse Drug Reactions. Second edition. London, UK: Pharmaceutical Press; 2007. p. 157-191.

40. Whelton A, Schulman G, Wallemark C, et al. Effects of celecoxib and naproxen on renal function in the elderly. Arch Intern Med. 2000;160:1465-1470.

41. Mamdani M, Juurink DN, Lee DS, et al. Cyclo-oxygenase-2 inhibitors versus non-selective non-steroidal anti-inflammatory drugs and congestive heart failure outcomes in elderly patients: a population-based cohort study. Lancet. 2004;363:1751-1756.

42. Mamdani M, Rochon P, Juurink DN, et al. Effect of selective cyclooxygenase 2 inhibitors and naproxen on short-term risk of acute myocardial infarction in the elderly. Arch Intern Med. 2003;163:481-486.

43. Lévesque LE, Brophy JM, Zhang B. The risk for myocardial infarction with cyclooxygenase- 2 inhibitors: a population study of elderly adults. Ann Intern Med. 2005;142:481-489.

44. Forman JP, Stampfer MJ, Curhan GC. Non-narcotic analgesic dose and risk of incident hypertension in US women. Hypertension. 2005;46:500-507.

45. Juurlink DN, Mamdani M, Kopp A, Laupacis A, Redelmeier DA. Drug-drug interactions among elderly patients hospitalized for drug toxicity. JAMA. 2003;289:1652-1658.

46. Stockley IH, editor. Drug Interactions. Fifth edition. London, UK; Pharmaceutical Press; 2000. p. 335.

47. Kaufman DW, Kelly JP, Rosenberg L, Anderson TE, Mitchell AA. Recent patterns of medication use in the ambulatory adult population of the United States: the Slone survey. JAMA. 2008;287:337-344.

48. Zermansky AG, Petty DR, Raynor DK, Freemantle N, Vail A, Lowe CJ. Randomised controlled trial of clinical medication review by a pharmacist of elderly patients receiving repeat prescriptions in general practice. BMJ. 2001;323:1340-1344.
Clinical Interventions in Aging

\section{Publish your work in this journal}

Clinical Interventions in Aging is an international, peer-reviewed journal focusing on evidence-based reports on the value or lack thereof of treatments intended to prevent or delay the onset of maladaptive correlates of aging in human beings. This journal is indexed on PubMed Central, MedLine, the American Chemical Society's 'Chemical

\section{Dovepress}

Abstracts Service' (CAS), Scopus and the Elsevier Bibliographic databases. The manuscript management system is completely online and includes a very quick and fair peer-review system, which is all easy to use. Visit http://www.dovepress.com/testimonials.php to read real quotes from published authors. 